\title{
Biochemical factors in the action of steroids on diseased joints in rheumatoid arthritis
}

\author{
*D. A. LEWIS AND E. H. DAY \\ Pharmacology Group, School of Pharmacy, University of Bath, and the Royal National Hospital for Rheumatic \\ Diseases, Bath
}

Lysosomal enzymes have been implemented in the pathogenesis of rheumatoid arthritis (Jacox and Feldmahn, 1955; Weissman, 1966). It has been suggested that the anti-inflammatory action of steroids is based on the ability of these drugs to stabilize lysosomes. However, much of the work on the interaction of steroids with lysosomes has been carried out on model systems such as liposomes or liver and kidney lysosomal preparations.

In this report we have examined the actions of steroids on tissues directly associated with rheumatoid arthritis.

DISTRIBUTION OF LYSOSOMAL ENZYMES IN SYNOVIAL TISSUES AND FLUIDS

Lysosomal enzymes have been demonstrated in several cell types of possible importance in the development of rheumatoid arthritis. Acid phosphatase has been demonstrated histochemically in chondroclasts (Schajowicz and Cabrini, 1958). Luscombe (1963) found that there were significant increases in acid phosphatase and cathepsin activity in the synovial tissues of patients with rheumatoid arthritis. Smith and Harmerman (1962) have postulated that the major source of acid phosphatase in synovial fluid is from polymorphonuclear cells. Lehman, Kream, and Brogna (1961) suggested that the lymphocytes were a further source of acid phosphatase in synovial fluid.

\section{ACTIONS OF STEROIDS ON LYSOSOMES}

It is an accepted fact that corticosteroids at some concentrations stabilize lysosomes. Previous work in this laboratory (Lewis, Symons, and Ancill, 1970; Symons, Lewis, and Ancill, 1970) has shown that steroid concentration is a critical factor in the stabilizing action of these compounds on lysosomes. High concentrations of steroids damage lysosomes, but lower levels, which have more clinical significance, stabilize lysosomes.
PURPOSE OF PRESENT STUDY

The objects of the experiments reported in this paper were

(1) To investigate the amounts of particulate-bound lysosomal enzymes in synovial membrane and in cells present in synovial fluid. These experiments were carried out on pathological specimens.

(2) To determine the effect of concentration on the action of steroids on lysosomes in synovial tissues.

(3) To determine the amount of steroid taken up by cells and to relate this amount to the action of the steroid on the cells.

(4) To relate the results obtained to the clinical treatment of the disease.

\section{Materials and methods}

Isolation of synovial fluid cells

The fluids were freshly aspirated from patients with rheumatoid arthritis. The affected joint in each case was the knee. The fluids were centrifuged at 7,500 r.p.m. for $25 \mathrm{~min}$. at $4^{\circ} \mathrm{C}$. The pellets were suspended in saline solution buffered at $\mathrm{pH} 7 \cdot 4$ with phosphate buffer. Portions of the suspensions were examined microscopically after staining with Leishman's reagent. The predominent cell type was the polymorphonuclear leucocyte (90-98 per cent.). Lymphocytes were present to the extent of 2-3 per cent. of the total cells. The suspensions were centrifuged and the cells washed with fresh saline. After a final centrifugation they were suspended in buffered saline. The volume of saline used was equal to the original volume of synovial fluid.

\section{Uptake of steroids by synovial fluid cells}

This method has been described by Symons, Lewis, and Ancill (1970). Essentially, the cells from the synovial fluids of patients with seropositive rheumatoid arthritis were suspended in phosphate buffered saline at $\mathrm{pH} \mathrm{7 \cdot 4.} \mathrm{Portions}$ $(1.5 \mathrm{ml}$.) of the suspensions were transferred to dialysis bags which were suspended in buffered saline $(10 \mathrm{ml}$.) 
containing radioactive steroids. The inactive steroid was used as carrier. In the controls the dialysis bags contained buffer saline solution alone. After 6 hours' incubation at $37^{\circ}$ (the time observed to be sufficient for maximum uptake of steroid) portions $(0.1 \mathrm{ml}$.) of the cell suspensions were transferred to scintillation vials and the amount of radioactivity present determined in a Packard Tri-Carb scintillation counting system. Portions $(0 \cdot 1 \mathrm{ml}$.) of the buffer in the dialysis sacs in the controls were also assayed for radioactivity. Differences between the control and experimental values gave the amount of steroid taken up by the cells. The results were corrected for quenching. The protein content of the cells was determined by the method of Lowry, Rosebrough, Farr, and Randall (1951). After portions of the suspensions had been removed for radiochemical assay, the remainder was centrifuged to remove cells, cellular debris, etc., and the supernatant assayed for $\beta$ - $\mathrm{N}$-acetylglucosaminidase and acid phosphatase.

\section{Effect of steroids on the fragility of lysosomes in synovial membranes}

Sections $(500 \mu)$ of synovial membrane, freshly obtained from synovectomy, were chilled and cut with a Stadie-Rigg microtome. The sections were suspended in oxygenated Krebs-Ringer solution $(30 \mathrm{ml}$.). Approximately $1 \mathrm{~g}$. (fresh weight) of tissue was used in each experiment. The sections were incubated at $37^{\circ} \mathrm{C}$., and portions of the suspending medium taken at various intervals. The samples were centrifuged to remove particulate matter and assayed for $\beta$ - $\mathrm{N}$-acetylglucosaminidase. In other experiments, solutions of the drugs in dimethyl sulphoxide solution were added to the Krebs-Ringer solution after the incubation had been allowed to proceed for $1 \mathrm{hr}$. The effect of the drug on the rate of release of the enzyme from the tissue was then determined. The controls were treated with dimethyl sulphoxide alone.

\section{A comparison of fragility of lysosomes in synovial membranes} removed from several patients with rheumatoid arthritis Synovial tissue was removed by synovectomy from six patients. The tissues were examined and assessed according to the degree of visual signs of inflammation. A description of the condition of the tissues of each patient at synovectomy is given below. In general, the synovial membranes of patients 1,2 , and 3 were highly inflamed. In contrast the synovial membrane of patients 4,5 , and 6 were only moderately inflamed.

Case 1, a 21-year-old woman, who had had seropositive rheumatoid arthritis since 1964, underwent synovectomy of the right knee on April 20, 1971. The synovium was found to be markedly hyperaemic and the intracondylar notch was hyperplastic. There was a small area of activity extending on the edges of the articular cartilage of the femoral condyle and more extensive activity around the corners of the intracondylar notch. There was complete loss of articular cartilage over the lateral femoral condyle and 70 per cent. loss on the medial femoral condyle. In general the synovium was markedly active with extensive erosion of cartilage.
Case 2, a man aged 44 years, who had seronegative rheumatoid arthritis, underwent synovectomy of the right knee on June 2, 1971. Moderate synovial activity was found over the sides of the medial and lateral femoral condyles. There was mild activity in the suprapatella pouch, moderate activity of the fat pad, but marked synovial activity of the intracondylar notch. There was complete loss of articular cartilage on the lateral femoral condyle but a thin layer of cartilage on the medial femoral condyle. In this patient there was a high activity of the synovium with moderately severe erosion.

Case 3, a 77-year-old woman, who had had seropositive rheumatoid arthritis since 1961, underwent synovectomy of the left knee on June 16, 1971. There was extensive hypertrophy and hyperaemia of the synovium over the medial and lateral femoral condyles, the fat pad, and the intercondylar notch. There was only moderate activity in the suprapatella pouch. The anterior cruciate was much attenuated but the posterior cruciate was normal. An area across the two condyles at the junction of the intercondylar notch was completely denuded of synovium. A thermogram of the knee before operation showed that it was very hot. In this patient there was an extremely active synovium with gross erosion of cartilage.

Case 4, a 52-year-old woman, who had had seropositive rheumatoid arthritis since 1959, underwent synovectomy of the right knee on May 21, 1971. The synovium was active over the lateral femoral condyle and suprapatella pouch. Activity was minimal on the medial femoral condyle, there was no activity over the patella, and the intracondylar notch was filled with low-grade rheumatoid tissue. There was a complete loss of articular surface over 80 per cent. of the femoral condyles with hard bone visible. In this patient the synovium was moderately active with considerable erosion.

Case 5, a 57-year-old man, who had had seropositive rheumatoid arthritis since 1948 , underwent synovectomy on June 18,1971 . The synovium was only moderately active. There was marked involvement of the femur and loss of all the normal surface with some fibrillation on the level of the junction of the two femoral condyles. The intracondylar notch was filled with fibrous tissue with some active synovium. In general the activity of the synovium was largely burnt out. There was gross erosion of the joint due to the long-term effects of the disease.

Case 6, a 67-year-old woman, had had rheumatoid arthritis since 1949. The synovium was moderately active with gross damage to the femoral condyles.

In each case the tissues were cut into thin sections with a Stadie-Rigg microtome and $1 \mathrm{~g}$. fresh weight of slices was incubated in oxygenated Krebs-Ringer solution solution at $37^{\circ}$. Samples of the medium were taken at various times and after centrifuging were assayed for $\beta-\mathrm{N}$-acetylglucosaminidase.

Distribution of lysosomal enzymes in the particulate fraction obtained from synovial membrane and synovial fuid cells Synovial tissue and fluids were obtained as fresh synovectomy material from seven patients. The synovial membrane was carefully dissected out from the fibrous 
capsular material and minced. The tissue was then homogenized in $0.25 \mathrm{M}$ sucrose and a lysosomal fraction subsequently obtained by ultracentrifugation (Symons and others, 1969). The lysosomes were suspended in 0.25 M sucrose buffered at $\mathrm{pH} 7 \cdot 4$ with tris- $\mathrm{HCl}$ buffer. The suspensions were frozen and thawed four times to rupture the lysosomes. The suspensions were centrifuged once more to remove lysosomal debris. The supernatants were assayed for acid phosphatase or $\beta-\mathrm{N}$-acetylglucosaminidase. The synovial fluid cells were isolated as described above. They were ruptured by freezing and thawing four times. After centrifuging to remove cellular debris the supernatants were assayed for acid phosphatase and $\beta$-N-acetylglucosaminidase.

\section{Results}

Distribution of lysosomes between synovial fluid cells and synovial tissues

The results from seven patients are summarized in Fig. $1(\mathrm{~A}+\mathrm{B})$. The histograms represent particulatebound acid phosphatase and $\beta$-N-acetylglucosaminidase.

Clearly the enzyme levels vary from patient to patient, but there appear to be significant amounts of enzymes in both the fluid cells and membranes.

One empirical observation of interest made by the surgeon was that 'hot' joints have given the highest enzyme values.

The values do not represent total enzyme levels since free levels were not determined. It was not possible to determine the distribution of free enzyme between synovial tissue, fluid, and cells because there would be contamination from one tissue compartment to the other.
Action of steroids on synovial fluid cells

The results recorded in Fig. $2(\mathrm{~A}+\mathrm{B})$ clearly show that the action of the steroid on the amount of lysosomal enzyme released is related to the amount of drug taken up by the cell. Also, when large amounts of the drug were taken up by the cell, the stabilizing action of the drug on the cell was diminished. At concentrations of clinical interest the drug exerted a stabilizing action on the lysosomes present in the cells.

Release of lysosomal enzymes from slices of synovial membrane removed from patients with rheumatoid arthritis

Fig. 3 shows that more lysosomal enzymes were released from the highly inflamed tissues (Cases 1, 2, and 3) than from the less inflamed tissues (Cases 4, 5, and 6). This may have been due to more lysosomes being present in the highly inflamed tissues or to the lysosomes present in these tissues being in a more fragile state. Clearly high lysosomal enzyme levels were associated with the severely inflamed tissues. However, from this type of experiment, it is not possible to state whether the lysosomal enzymes present caused the inflammation or whether the high lysosomal enzyme levels were present as a consequence of the inflammation.

Action of steroids on the release of lysosomal enzyme from synovial membrane

The effect of steroids on the release of lysosomal enzymes from slices of synovial membrane is given in the Table. The results are given as percentages of the control values, where the control values have been
(A) ACID PHOSPHATASE LEVELS

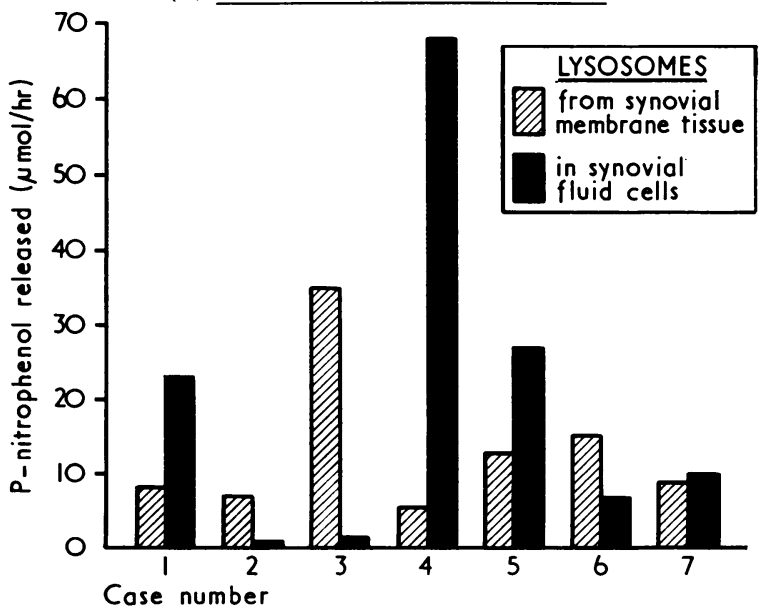

(B) $\beta$-N-ACETYLGLUCOSAMINIDASE LEVELS

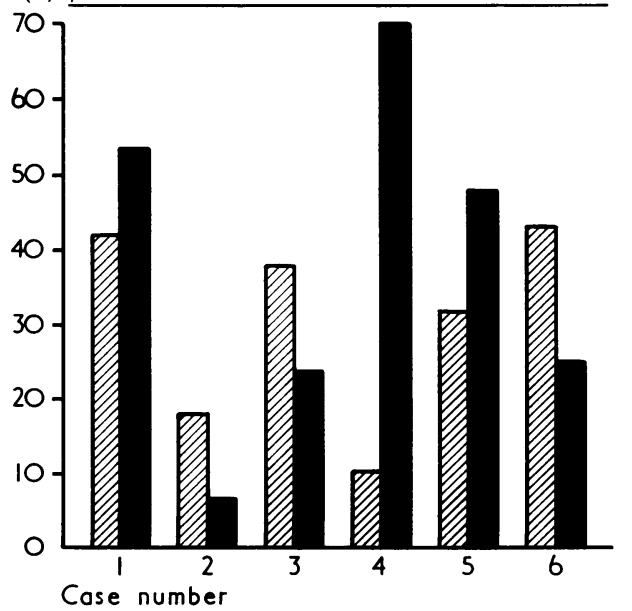

FIG. 1(A + B) Distribution of lyosomes between synovial fluid cells and synovial tissue. Fluid values in $\mu$ moles $p$ nitrophenol released $/ \mathrm{hr} / \mathrm{ml}$. Tissue values in $\mu$ moles p-nitrophenol released $/ \mathrm{hr} / \mathrm{g}$. (fresh weight) tissue Acid phosphatase levels alone were determined for Case 7 

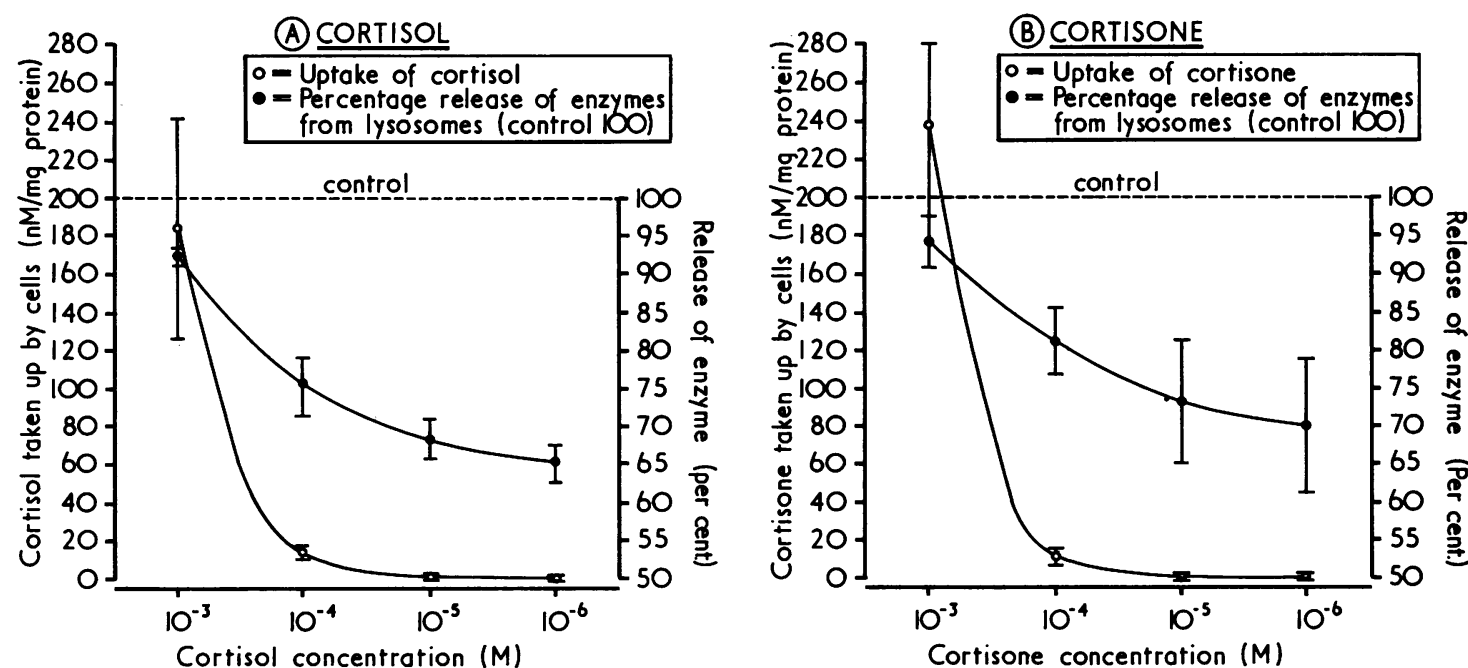

FIG. 2(A +B) Amount of steroid (A. Cortisol; B. Cortisone) taken up by synovial fluid cells at various steroid concentrations. Effect of steroid on release of $\beta$ - $N$-acetylglucosaminidase from lysosomes.

- Uptake of cortisol.

- Percentage release of enyme from lysosomes compared with a control value of 100.

Results are mean values \pm standard deviation for three experiments

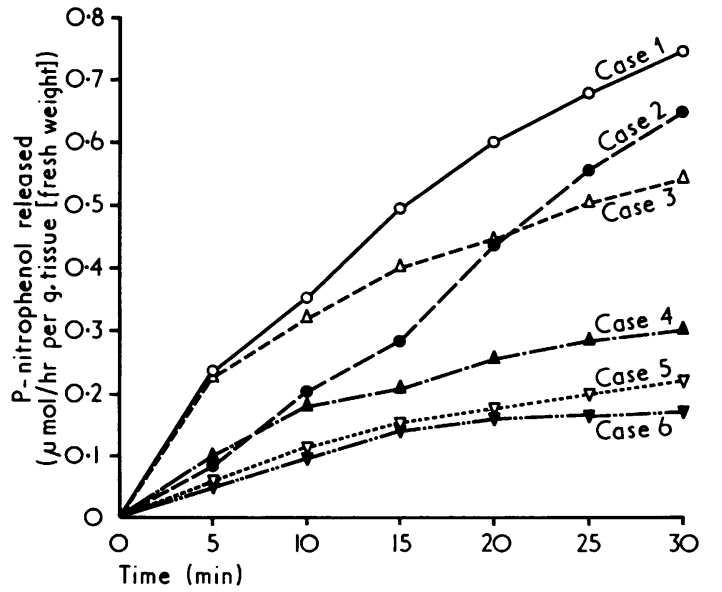

FIG. 3 Release of lysomal enzymes from slices of synovial membrane. A clinical description of each patient's condition is given in the text

adjusted to 100 per cent. Values below 100 represent a stabilizing action by the steroid on the lysosomes but values greater than 100 represent a labilizing action. Clearly steroids at concentrations of clinical interest have stabilized the lysosomes. However, high concentrations of steroids have induced lysosomal breakdown. These results parallel the action of steroids on lysosomes in the cells isolated from synovial fluids.

\section{Discussion}

The results are consistent with the theory that steroids may exhibit their anti-inflammatory action
Table Effect of prednisolone on the amount of $\beta$ - $N$-acetylglucosaminidase released from synovial membrane

\begin{tabular}{|c|c|c|}
\hline \multirow[t]{2}{*}{ Time (min.) } & $\begin{array}{l}\text { Percentage release } \\
\text { aminidase at steroid }\end{array}$ & $\begin{array}{l}\text { of } \beta-\mathrm{N} \text {-acetylglucos- } \\
\text { concentrations of }\end{array}$ \\
\hline & $10^{-4} M$ & $10^{-6} M$ \\
\hline $\begin{array}{r}5 \\
10 \\
15 \\
20 \\
25 \\
30\end{array}$ & $\begin{array}{l}135 \pm 25 \\
134 \pm 20 \\
149 \pm 29 \\
144 \pm 27 \\
137 \pm 23 \\
141 \pm 29\end{array}$ & $\begin{array}{l}82 \pm 15 \\
61 \pm 6 \\
73 \pm 12 \\
73 \pm 9 \\
71 \pm 8 \\
74 \pm 6\end{array}$ \\
\hline
\end{tabular}

through stabilising lysosomes. However, it is clear that steroid concentration is an important factor. The lytic action of steroids on the cells and membranes is of interest since the release of lysosomal enzymes into the joint may induce an inflammatory response. It is known that occasionally intra-articular injections of steroids produce a short-lived inflammation. Collins and Cosh (1970) have observed that the intra-articular injection of steroids produces a temporary rise in lysosomal enzyme levels. Subsequently these levels fall as the inflammation subsides. Lewis, Capstick, and Ancill (1971) have shown that gastro-intestinal ulceration may be due to the action of drugs on lysosomes. In general the results are similar to those previously obtained with liver lysosomes with one important difference. The synovial fluid cells appear to be target cells for steroids in that they have taken up ten times as much 
steroid per mg. protein as liver lysosomes (Symons and others, 1970). This finding would appear to warrant further study, since it may explain why steroids administered by the oral route exert an antiinflammatory action on diseased joints. It is possible that synovial tissues and cells are targets for antiinflammatory steroids.

Although this paper suggests that steroids exert their anti-inflammatory action through a direct interaction with lysosomes, it must be borne in mind that the steroid concentration in the joint is constantly changing because of metabolism and other causes. Of interest are the findings of Murphy and West (1969) that synovial tissues metabolize steroids and that diseased tissues may produce a different pattern of metabolites from normal tissues. It may well be that the distribution of steroids within the tissues and cells is a key factor in their action.

Whether lysosomes are directly involved in producing inflammation, as suggested by the Hollander theory, or are indirectly involved as part of a sequence of events, as suggested by our findings with arthritic rats (Collins and Lewis, 1970) or the observations of Collins and Cosh (1970) on levels of lysosomal enzyme levels in human synovial fluids, the interaction of steroids with lysosomes appears to be an important factor in their mode of action.

\section{Summary}

(1) The distribution of lysosomes between synovial fluid cells and synovial membrane has been investigated. Both the membranes and the cells were found to contain considerable quantities of lysosomes, particularly where the specimens were highly inflamed.

(2) Synovial fluid cells were found to concentrate steroids from solution. The amount of steroid taken up by the cells was related to the action of the drug on the stability of the lysosomal membranes present. The lower concentrations of steroids induced stabilization of the lysosomes, but at higher concentrations the stabilizing action of the steroids diminished.

(3) Slices of synovial membrane were examined for lysosomal enzyme levels. It was found that samples from patients with 'hot' joints released greater quantities of enzymes than those from patients with less inflamed tissues. Prednisolone at a concentration of $10^{-6} \mathrm{M}$ was found to stabilize the lysosomes in these tissues, but at a concentration of $10^{-4} \mathrm{M}$ the steroid induced lysis.

(4) The clinical implications of these results are discussed.

We wish to thank the Arthritis and Rheumatism Council for financial support and the Royal Society for a grant to purchase a Packard scintillation counting system. We are also grateful to the surgical and medical staff of the Royal National Hospital for Rheumatic Diseases and the Bath and West Orthopaedic Hospital for surgical material and helpful discussions. In particular, we should like to thank Mr. P. M. Yeoman and Mr. I. Pinder. We should also like to thank Prof. R. J. Ancill for his help and encouragement.

\section{References}

Collins, A. J., AND Cosh, J. A. (1970) Ann. rheum. Dis., 29, 386 (Temperature and biochemical studies of joint inflammation)

-, AND LEWIS, D. A. (1971) Biochem. Pharmacol., 20, 251 (Lysomal enzyme levels in the blood of arthritic rats)

JACOX, R. F., AND FeldMAHN, A. (1955) J. clin. Invest., 34, 263 (Variations of $\beta$-glucuronidase concentration in abnormal human synovial fluid)

Lehman, M. A., Kream, J., AND Brogna, D., (1964) J. Bone Jt. Surg., 46-A, 1732 (Acid and alkaline phosphatase activity in the serum and synovial fluid of patients with arthritis)

Lewis, D. A., CAPSTICK, R. B., AND ANCILL, R. J. (1971) J. Pharm. Pharmacol., 23, 931. (The action of azapropazone, oxyphenbutazone and phenylbutazone on lysosomes)

-, Symons, A. M., AND ANCILL, R. J. (1970) Ibid., 22, 902 (The stabilization-lysis action of anti-inflammatory steroids on lysosomes).

Lowry, O. H., Rosebrough, N. J., Farr, A. L., and Randall, R. J. (1951) J. biol. Chem., 193, 265 (Protein measurement with folin phenol reagent)

LuscomBe, M. (1963) Nature (Lond.) 197, 1010 (Acid phosphatase and catheptic activity in rheumatoid synovial tissue)

MURPHY, D., AND WeST H. F. (1969) Ann. rheum. Dis., 28, 637 (Catabolism and interconversion of cortisol and cortisone in human synovial tissue in vitro)

SchaJowicz, F., AND CABRINI, R. L. (1958) Science, 127, 1447 (Histochemical localization of acid phosphatase in bone tissue)

Smith, C., AND Hamerman, D. (1962) Arthr. and Rheum., 5, 411 (Acid phosphatase in human synovial fluid)

Symons, A. M., Lewis, D. A., AND ANCILl, R. J. (1969) Biochem. Pharmacol., 18, 2581 (Stabilizing action of anti-inflammatory steroids on lysosomes)

anti-inflammatory steroids on lysosomes)

WeissmanN, G. (1966) Arthr. and Rheum., 9, 834 (Lysosomes and joint disease) 